\title{
Digitalization: The new extraterritorial challenge to extraterritorial obligations
}

\author{
Nicoletta Dentico, Mohammed El Said and Giacomo Capuzzo
}

Governments have certainly not regulated the tech industry as if human rights were at stake, and the technology sector remains virtually a human rights-free zone.

Philip Alston, UN Rapporteur on extreme poverty and human rights

\section{The good, the bad, and the ugly of the digital revolution}

More than ever, digitalization is all around us. For years, carried away by the fascination with digital gadgets and technologies, we have been allured to blindly enter a world of sophisticated machines without taking into consideration where this journey would take us and how it would revolutionize our existence - to the extent of taking over our human ability to control life. In such unaware mood, we have ceded much of our decision-making power to sophisticated invisible digital systems that have penetrated our daily lives. Only in recent months, since the outburst of COVID-19 has halted our ordinary lives, have we been able to get a better sense of the reality of transformation we have been in for some time. The internet has eased lockdown life for millions, digitalization and the web have been the critical unifying forces enabling work from home, school through online classrooms, social activities and mutual support and solidarity at a healthy distance. Policymakers have managed the unprecedented situation, and their international negotiations, through virtual meetings.

What do we mean with the term digitalization? Digitalization is a concept that lacks a single clear definition (IGI Global 2018), and is fraught with ambiguity. Brennen and Kreiss define it as 'the way in which many domains of social life are restructured around digital communication and media infrastructures' (Brennen and Kreiss 2016, p. 3). The Gartner Glossary focuses on business models rather than social interactions and describes digitalization as 'the use of digital technologies to change a business model and provide new revenue and value-producing opportunities; it is the process of moving to a digital business' (Gartner Glossary). We propose a third definition: 'the ongoing adoption of digital technologies across all possible societal and human activities' (IGI Global 2018).

For good or bad, the new coronavirus pandemic has accelerated and will further accelerate the shift towards digitalization globally. This historic jump reanimates the dilemma between law and technology, and risks creating itself significant human rights challenges. Governments have 
to keep up with technology to play the role they must, with any industry. But as often the case, national and international laws lag behind technological developments, intellectual property being a recent example: after 20 years of negotiation, in 1995 the Trade Related Aspects of Intellectual Property Rights (TRIPS) Agreement at the World Trade Organization (WTO) was born deficient as it did not address the rise of the internet. State regulators are now struggling with insurmountable obstacles in dealing with apps that are reshaping the world at incredible speed, with rampant extraterritorial dynamics. Platforms like Google Alphabet, Facebook, or TikTok operate outside the jurisdiction of most countries, while the few regulatory frameworks in place lack the agility to accommodate the increasing pace of digital development. Moreover, digitalization deeply challenges the way governments regulate as it can easily bail out enforcements, transcend administrative boundaries domestically and internationally (OECD 2019), hence exposing less powerful countries to a digital wild west. While it spurs new regulatory needs, digitalization cannot be dealt with using old rules.

States have obligations to limit any potential unintended negative consequences, but the reality is that digital tools are already being used to crack down on civil and political rights. According to accredited analysts, automation, robotics, drones, and remote sensing will bear the undesirable consequences of a high-tech dystopia providing cover for those ready to implement a raft of oppressive social practices associated with the tech industry (Klein 2020). In many countries, systems of social protection and assistance are increasingly driven by digital data and technologies used to automate, predict, identify, surveil, detect, target, and punish (Burgess 2020). The process is neutrally denominated 'digital transformation', but the inoffensive term should not be allowed to conceal the revolutionary legal and political connotations of such innovation, leading to the expansion of a new form of governance, with extraterritorial implications. At the dawn of the Fourth Industrial Revolution electronic voting, technology-driven surveillance including through facial recognition programs, algorithm-based predictive policing, the digitalization of justice (Marr 2020) and immigration systems (Blix 2017), online submission of tax returns and payments (OECD 2018), and many other forms of electronic interactions between citizens and different levels of government have become an irresistible attraction. With the avatar of the internet of things, the embrace of digital welfare is pursued in the name of efficiency and with a reduction of public spending (Marsh 2019), but UN Rapporteur Philip Alston alerts that it risks 'becoming a Trojan Horses for neoliberal hostility towards social protection and regulation $[\ldots]$ and a complete reversal of the traditional notion that the state should be accountable to the individual' (Alston 2019b). The policy bias proclaims the benign intention of an interconnected open society that promotes responsibility and fosters individual autonomy, but through the processing of immense quantities of digital data, it relies on automated predictions/decision-making, gradually distancing and de facto removing the human factor. As Philip Alston points out, "citizens become ever more visible to their governments, but not the other way round' (Alston 2019b).

States' obligations painfully struggle with the digital acceleration being under the primary control of private entrepreneurs whose main interest is to operate in an environment with minimum legal constraints. Regulators fail to get a deeper understanding of the emerging technologies' institutional and transboundary challenges, and their potential consequences for society. Meanwhile tech titans generate endless profits through their platforms, as we are seeing in pandemic times (Mattioli 2020). They benefit from the 'networks effects': size begets size. In providing the infrastructure for the digital convergence, they don't compete in the market. They are the market.

Is it too late, to ring the alarm? Difficult to tell. While possibly nothing more extraterritorial exists than digital technology, regulating this sector in the mismatch between its transboundary 
nature and the regulatory fragmentation undermines the effectiveness of any action and may generate barriers to the spread of beneficial digital innovations. Solutions limited to domestic domains are not an option. Specific, extraterritorial institutional responses are urgently required. Even more so following the pandemic.

\section{Unequal access to digital rights, and digital tools used against human rights}

Almost the entire world population lives within reach of a mobile network; still, a gross digital divide still holds back roughly half of the planet (ITU 2020). A huge digital rights gap marks the line between those who have internet access and those who don't. The three-decades-long drive to connect the planet was relatively easy in the high-income countries, where financial availability, good education, and dense urban centres smoothened the way to connectivity. Getting the rest of the nations online will be far more difficult ${ }^{1}$, despite apparent political attention and the Sustainable Development Goal (SDG) 9 which aims to "significantly increase access to ICT and strive to provide universal and affordable access to the internet in least developed countries by $2020^{\prime}$ (SDG, target 9c) ${ }^{2}$.

In fact, the pace of growth of internet across the globe has slowed down significantly since 2015: from 19\% in 2007 to less than 6\% in 2017 (Sample 2018); the digital revolution will continue to be a hard option for the most marginalized people. Digital disparity hits Africa, where only $1 / 4$ people can access the $w^{3} b^{3}$, the hardest. Investments by operators have either stalled or declined in recent years, and the level of costs for internet access remains a key driver of the digital inequality. The UN Target for affordable internet is $2 \%$ of monthly income for one gigabyte of data - the threshold deemed to permit basic internet access. Only the richest $20 \%$ of South Africans can actually afford this. For the poorest $60 \%$ of the people in South Africa, such basic access costs between $6 \%$ and $21 \%$ of their monthly earnings. In Mozambique, one of the poorest nations, practically nobody can afford the internet (A4AI 2014). Universal access will not be realistic before 2050 or later (Sample 2019).

Literacy is the other stumbling block, and another reasons of women's exclusion. Men are $21 \%$ more likely to have online access, and $52 \%$ in the lowest income countries (Iglesias, Web Foundation 2020). The digital gender gap continues to grow, particularly in Arab States, Asia and the Pacific, and Africa (ITU 2020, p.4). Against this asymmetry, digitalization has engineered new forms of violence against women and fueled new abuses of women's bodies. Web violence against women has taken up a disproportionate level of pathology, with new pandemic forms: from cyber-stalking to revenge porn, from doxing to sexting. The international human rights law provides standards to govern state and company approaches to online expression (A/HRC/38/35), yet the pervasiveness of the phenomenon in the digital environment actually hinders the process of advancing its conceptual and juridical definition, as illustrated by the European Commission work on hate speech online $e^{4}$. The intersection of online hate speech, freedom of expression, and inequality should provide space for governments' human rights legislation but, as UN Rapporteur David Kaye remarks:

New laws that impose liability on companies are failing basic standards, increasing the power of those same private actors over public norms, and risk undermining free expression and public accountability. Companies likewise are not taking seriously their responsibilities to respect human rights. It is on their platforms where hateful content spreads, spurred on by a business model and algorithmic tools that value attention and virality. 
They have massive impact on human rights and yet all fail to articulate policies rooted in human rights law, as the UN Guiding Principles on Business and Human Rights call upon them to do.

(Kaye 2019)

In 2020, COVID-19 has exposed the digital divide like never before. Among the many inequalities revealed by the pandemic, this manifestation is one of the starkest and most surprising. It stretches well inside the wealthiest nations, where access to internet infrastructures is definitely lower than we might have assumed before COVID. In the US, roughly 12 million children are estimated to live in homes without broadband connectivity (US Congress 2017). In the UK, 60,000 children have no internet at home (UK Children's Commissioner 2020) and many more were prevented from online learning with schools closed (Montacute 2020). Ultimately, while we all inhabit this brave new world of digital data, not everybody experiences it in the same way. Lack of access and tools is one side of the coin. Not the only one.

As more services are moving online, the divide is growing because digitalization has increasingly been used, like previous technological innovations, with the purpose of smothering economic and social rights, through profiling and containing marginalized groups. In the absence of national or international legal instruments to discipline the operations of digital tools - particularly algorithms - within the decision-making processes of private and public actors, and the potential discriminatory effects resulting from such use $\mathrm{e}^{5}$, the riveting sequence of precarious lives vulnerated by bad data, software errors, and unfit bureaucrats in Virginia Eubanks' powerful book is but the display of the hideous outcome (Eubanks 2018). Addressing the sources of discrimination and remedying the corresponding deficiencies in the law is not only technically difficult, but challenging also from a legal and political perspective. Yet, the skyrocketing precariousness for millions of people after the 2008 global financial crisis has been chaperoned by an equally swift increase of sophisticated data-based technologies like predictive algorithms, automated eligibility systems, risk models in public administration services that are being rationalized in the name of efficient social protection, so as to better help those who are really in need. The uptake of these technologies is rampant at a time when social schemes that serve the impoverished working class and other segments of society are as unpopular as they have ever been (Buchanan 2019), not by coincidence. In terms of litigation outcomes, victories in these cases are based on claims that challenged the lack of notice, explanation, and ability to comment or contest the changes to public benefit systems. This was especially relevant for the plaintiffs, individuals with intellectual or developmental disabilities:

However, as systems become more widely adopted and accepted across different jurisdictions and domains, and affect different demographics, these challenges may be harder to bring, at least on grounds that challenge lack of notice. It is also worth noting that these challenges and the resulting mitigation efforts are extremely resource intensive, which can serve as an additional barrier for advocates.

(AI Now Institute 2018, p.8)

Meanwhile, the increasing number of poor face higher levels of electronic scrutiny when they are processed for access to public benefit services or the healthcare system, when they walk highly policed neighborhoods or cross national frontiers, unknowingly entering a new digital infrastructure of poverty relief: 'a "low rights environment" where there are few expectations of political accountability and transparency' (Eubanks 2018, p.8). A 'digital poorhouse that 
hides poverty and gives society the needed ethical distance to design and implement inhumane policies' (Eubanks 2018, pp. 174-200).

\section{Artificial intelligence and the digital anthropomorphic metamorphosis}

In his investigation on artificial intelligence, French philosopher Éric Sadin argues that we have definitely entered a post-digital era or, more precisely, a digital technology's anthropomorphic era (Sadin 2019). We cannot grasp it yet, but given the power currently held by digital technologies it is urgent that we recognize how their features and functions entirely define a break from their original conceptualization. Tech anthropomorphism is peculiar: modelled on human cognitive capacities but enhanced to be more rapid, reliable, and efficient; fragmented, to solely perform specific tasks; enterprising and extreme, capable not only to interpret data, but also to start automatically goal-oriented actions.

We are confronted with the inexorable insurgence of an algorithmic aletheia (truth), which is literally in the hands of Western tech monopolies, determining the trajectory of digital research, and interpreting any single life moment as a beneficial opportunity for never-ending capital generation (and accumulation). Their models are 'black boxes' whose contents are fiercely guarded corporate secrets (Szymielevicz 2020). Beyond their aura of genial creative rebellion (Giridharadas 2019), tech titans escape tax bills alongside regulations and are accused to be 'BAAD - big, anti-competitive, addictive and destructive to democracy' (The Economist 2018, p.11). Preaching the idea of 'building a new global community' (Zuckerberg 2017), they run their business of math-powered applications driving the data economy and the instauration of a new order of things based on maximum reactivity and return. An order to which all segments of society - individuals and their life style, workforce, public institutions, hospitals, schools, transport networks, companies - must adapt and respond, almost outside of any territorial jurisdiction.

The anthropomorphist orientation of algorithmic sciences is - for the first time in human history - trying to endow digital artefacts with the human capacity to evaluate situations and extract conclusions. Modelled on the human brain, computational architectures are enabled to improve their competence via algorithms that help them rapidly retain and stock any new elements and data, thus asserting their truth in orienting human actions. Their improved ergonomic features allow them to get closer to human bodies and minds (to exercise their incremental 'powers of enunciation': incentivizing, imperative, prescriptive, and coercive (Sadin 2019, pp. 65-92).

Their incentivizing power thrives through the deployment of 'conversational interfaces' and voice-controlled personal assistants (chatbots) that may be installed anywhere, to map our tropisms and interests, in unpredictable forms of daily body contacts that imperceptibly mark the slow shift from control to a psychological relation of surrender and addiction (Dilci 2019). Chatbots form the backbone of the 'conversational commerce' featuring the economy of attention attention being the digital age's most valuable asset (Mintzer 2020).

The imperative enunciation dominates justice digitalization, the automated management of people's profiles and the credit score system used in selection processes, used for behavioral modification (AI Now Institute 2018, p.10). The prescriptive stage grows in the decision-making capacity of precision medicine and in police surveillance procedures, while the coercive vocation moves in the military industry's digitalization of the battlefields (ICRC 2017) and in companies' warehouses, where expert systems tell human personnel which items to pick up from which shelves, which fastest routes to take to optimize time (reorienting their route if humans autonomously decide otherwise). Coercive are the irregular working schedules intentionally adopted with lowwaged workers, where algorithms treat people as cogs in a machine (O’Neil 2016, pp.123-140). 


\section{Artificial intelligence: definitions (Serokell 2020)}

Artificial intelligence (AI) studies ways to create computers and machines capable of solving problems through intelligent behavior. Some researchers make a distinction between 'narrow $\mathrm{Al}^{\prime}$ and 'general $\mathrm{Al}^{\prime}$.

Narrow AI focuses on a single subset of cognitive abilities and advances in that spectrum, like computer systems that are better than humans at specific tasks (generating images, diagnosing diseases, playing chess).

General Al allows a machine to apply knowledge in different contexts, more closely mirroring human intelligence, by providing opportunities for autonomous learning and problemsolving, with generalized learning capabilities. Research progress is facilitating the transition from narrow Al to general Al, i.e. decision-making processes without explicit instructions.

Machine learning (ML), a subset of artificial intelligence, focuses on teaching computers how to automatically learn and improve without being programmed for specific tasks. ML aims to create algorithms that learn and make predictions based on data (neural networks). By using these neural architectures, it can reach out to higher levels of complexities.

Deep learning (DL) has steered the most significant breakthroughs in Al recently. It is a subset of machine learning that 'learns' from unsupervised and unstructured data processed through algorithms with brain-like functions, neural networks. Neural networks can develop through training (using different algorithms and improving them over time though incorporating new data sources) and inference (when a machine can identify which data sources are needed to make predictions).

The paradigm shift is supported by a robust rhetorical structure, blindly unchallenged. A new sophisticated lexicon has been crafted (Malabou 2017) to borrow the jargon from cognitive sciences, linked to the increasing ergonomic qualities of the products, towards a technoideology which allows the mix between cerebral processes and socio-economic logics. We need to re-conceptualize international legal protection in this field: human enhancement through such technologies is the primary human rights challenge of our time.

\section{The automated invisible hand: The challenge for states' regulatory obligations}

AI is the new gold rush. Governments and private companies are engaged in the global race to the AI podium, as the promising route for the next economic expansion. The race appears crowded with runners, but few are the real champions in this arena, indeed a national security concern with many geopolitical implications. In 2017 Vladimir Putin declared that 'whoever becomes the leader in this sphere will become the ruler of the world' (Allen 2017). The US has long steered public and private artificial intelligence research and development (R\&D); investments by venture capitalists have skyrocketed in less than a decade, with a financial wave that has molded several US organizations into relatively sophisticated AI users (Loucks, Jarvis and others 2019). But it is no longer alone. Despite lack of technological maturity, the Chinese government is determined to become the world's leading AI innovator by 2030, leapfrogging global competition with tens of billions of dollars investments in AI R\&D (Deloitte 2019). US and China together account for $90 \%$ of the market capitalization value of the world's 70 largest digital 
platforms (UNCTAD 2019); preoccupation is mounting about this concentration morphing into a duopolistic race between two digital superpowers ${ }^{6}$, where countries may one day have to choose sides, with potentially significant geopolitical implications. The European Commission's concern is about the leadership of the European digital economy, as expressed in its thriving sequence of initiatives in this field (Hilty 2018): Germany aims to accelerate the AI development and adoption with a holistic strategy, focused also on the need for a responsible use of the technology and its impact on the German workforce (Loucks, Jarvis and others, Deloitte 2019). France's 'AI for Humanity' reflects plans to transform the country into a global AI hub (Loucks, Jarvis and others, Deloitte 2019). The UK is exuberantly betting on the future of AI, like Israel, Japan, and South Korea. Saudi Arabia has created a ministry on artificial intelligence. In the promises of the Fourth Industrial Revolution, AI is the new golden calf, but there is hardly any Moses willing to grind the idol into the powder of its complexity.

Rather, the opposite. In 2017, the $73^{\text {rd }}$ session of the UN General Assembly invited robot Sophia ${ }^{7}$ to address governments about 'the future of everything', making it the first humanoid celebrity in history ${ }^{8}$. After Sophia's interaction with member states at the UN, Saudi Arabia granted citizenship to the genderless robot (Walsh 2017), while still depriving human women of their basic rights and criminalizing LGBTIQ. In this state of euphoric confusion, the UN Secretary General decided to create a high-level panel on digital cooperation in 2018, appointing tech tycoon Jack Ma and Melinda Gates as co-chairs (UN Digital Cooperation 2018).

The lack of global governance mechanisms for the use of digital technologies - including in the public domain - and their commercialization remains one of the toughest issues (Daño and Prato 2019). Big tech companies of course work hard to increase their footprint in the digital space and keep the scenario that way, based on the assumption that the ability to innovate demands freedom. The Facebook founder's early call for the tech industry to 'move fast and break things' epitomizes the relevance attached to removing legal and governmental constraints. As mentioned earlier, the traditional notion of liability is at stake, including the attribution of responsibility for harm caused to end users, particularly when dealing with the transversal challenges raised by digitalization. Ownership of the knowledge created by AI affiliated technologies is also a major threat. Gathering patients' details and commercializing them in the health industry, for example, has very controversial legal implications, since the medical knowledge owned by public institutions should be treated as a public good and used as such. Another uncomfortable question is how current legal regimes are to deal with machines as creators of knowledge. The intellectual property (IP) regime grants protection to a known inventor: how will the patent be managed if the machine is the inventor of a new antibiotic, for instance? In the fragmentation of regulatory jurisdictions, who will enforce these rights and how, across borders?

The international initiatives recently undertaken to provide principles and guidelines ${ }^{9}$, especially in using artificial intelligence, reveal the mounting sense of alert but do not yet really attack the regulatory roots of the problem. The European Union has embarked in the process of constructing a complex set of regulations for establishing and supporting a digital single market $(\mathrm{DSM})^{10}$ among the most crucial structural policies currently in train (European Commission 2020), with the primary intent of recalibrating the current legal frameworks. A case in point is the General Data Protection Regulation (GDPR) (European Union 2016), to confer all EU residents more control over their data. However, how will GDPR interact with AI and machines obtaining, processing, and producing data? Centralization, the backbone of the digital economy's regulation in Russia, does not seem quite compatible with the requirements of a digital scenario (Shatkovsskaya, Epifanova et al. 2018). Determining appropriate policy approaches is inherently difficult, the dynamic pace of technological change proceeds faster than legislative solutions and the key resources of the digital economy - intelligence and data - are invisible to current 
regulatory texts. Piecemeal regulatory efforts, like huge fines or sanctions, have failed to make any significant dent; 'the problem here may be that the regulators are trying industrial era remedies on digital age problems. Digital economy paradigm must be understood in its significant discontinuities with the industrial age. Regulation of digital economy needs to focus on the central role of data and data-derived intelligence' (Jeet Singh 2020, pp. 20-21). It has been highlighted that the outbreak of the new coronavirus reveals a digital governance emergency of international concern (McDonald 2020a), in a 'technological wild west' that deepens inequalities (Saez and Zucman 2019) and allows a bare handful of powerful CEOs to determine the disquieting sense of direction societies will take (Zuboff 2019). This emergency affects low- and middle-income countries (LMICs) disproportionately. Meanwhile, the debate on the human rights obligations of domestic states, foreign states, and transnational corporations, on who are the new duty bearers and the right holders, is painstakingly developing in official diplomatic fora; but attention to the legal uncertainty enveloping digital transformation remains limited ${ }^{11}$.

\section{The Hippocratic Oath reloaded}

Digital technologies have been hailed in recent years as the most promising solution to tackle health challenges and help address healthcare inequalities, and they have gained, if possible, new impetus with COVID-19, in the public health response to the pandemic worldwide. Digital epidemiological surveillance, online data sourcing for early detection, contact tracing, rapid case identifications, and data-visualization tools for decision support are being extensively harnessed and combined ${ }^{12}$, leveraging a significant breadth of innovation and investments. While technologies are obviously crucial to the disaster response, the digital hype against COVID-19 should not obfuscate the fact that technologists' blind spots and biases have already generated poisonous systems (Chesney and Citron 2018); the science community must ask itself a few fundamental questions to avoid that the tech rush may add to the chaos and ultimately injure the fight against the new coronavirus (Kalluri, Gillespie et al. 2020). The riddle goes beyond COVID: 'the way that we enable, administer and check the exceptional surveillance and social powers that each government exerts to contain COVID-19, especially as implemented through technology systems, will frame an important part of the future of state power in a world with increasing emergencies' (McDonald 2020b).

The future of public health is bound to become digital, in a swirling kaleidoscope of progress, expectations, limitations, and dilemmas (Budd et al. 2020): computational systems are quickly becoming the new frontier in healthcare, creeping out of their labs and making their way into supporting real people take real medical decisions. Despite their reputation for impartiality, they hammer complexity into simplicity and they always reflect goals and ideology: hence, their unflinching verdicts need serious scrutiny. At the Winterlight Labs, a Toronto-based startup that uses speech technology to assess cognitive health (for diseases like Alzheimer, Parkinson, and multiple sclerosis) language was the built-in bias - it only worked for English speakers of a particular Canadian dialect, leaving everyone else behind (Narayan 2019). A striking racial bias was identified in an algorithm used across America by hospitals and insurance companies to predict which patients were most likely to need follow-up care (Obermeyer, Powers et al. 2019). Hospitals and health systems are increasingly being structured on the premise that these systems are the future, gathering 'a bunch of data on previous patients, and use it to predict what will happen when a new patient steps in the door' (Gershgorn 2018). The clinical validity of this approach remains theoretical. From a human rights perspective, it means that the most vulnerable and powerless in society are subject to demands and forms of intrusiveness without accountability (Hawi, Samaha, Griffiths 2019) (Kickbush 2020). 
Since the ' 90 s, the progressive introduction of digital instruments and recording for medical exams has transformed medicine into a data generating practice, a trend that has formidably enhanced precision medicine (PM) and its armamentarium. PM methods seek treatments or prevention measures that are specifically tailored to an individual's disease process and symptoms and has received multibillion dollars in the last decade, to the detriment of key potential investments in population-based preventive programs that consider the behavioral, environmental, or social determinants of health (Ramaswami, Bayer, and Galea 2018). The first human genome sequenced in 2001 has stimulated the development of DNA-sequencing methods that have contributed to massive data availability and to a revolution in medical work and drug discovery, catering to the needs of high-income countries, where most research is conducted. The co-optation of medical and biological abilities as data hounds has been accepted by healthcare providers as an inevitable evolution, and the cheerleading medical literature has flourished to announce the provision of new instruments to better promote diagnosis, treatment, rehabilitation, and recovery. While there is no way to deny the real life improvement of this booming phenomenon, it is necessary to dig into some of its downsides for the right to health. The hyperindividualization of medicine supported by digital tools has further skewed health towards pharmaceutical approaches and forged a culture of personalized outcome improvements that are used by the private sector, especially the insurance industry, leaving behind key concerns for population health and the industry regulations required to this end. High costs are associated with digital health innovation, be it for individual users or societies; while commercial actors always reap heavy rewards, the solutions are not necessarily cost-effective for public authorities. Moreover, very few of the health apps comply with regulatory processes or have had their effectiveness formally assessed (Duggal, Briddle, and Bagenal 2018).

From a human rights' angle, digital devices have exacerbated existing power relations replicating and even reinforcing inequalities in very different ways, depending on their context of implementation (Al Dahdah 2019, pp.101-119;Al Dahdah 2020, pp. 39-69). In some countries, health data are used to structure public welfare programs and establish social credit scores; in others, they serve to sell goods and market services based on 'the starting assumption that the individual is not a rights-holder but rather an applicant' who must satisfy eligibility criteria (Alston, A/74/48037 2019, p. 14). For example, employers engaged in the constant quest for lowering costs have new tactics to fight growing insurance premiums - in the US these are encouraged by the Affordable Care Act (Obamacare) (Cawley 2014, pp. 810-820) - which involve greater workers' surveillance. The good justifications for the so called 'wellness programs' aimed to incentivize health conceal new forms of intrusion and coercion for the worker, who must follow a host of health behavioral dictates. Those who cannot reach the company's targets are compelled to pay extra contributions (fines?) to their insurance company, or likely undergo humiliating practices triggered by a mysterious proprietary algorithm (O’Neil 2016, pp. 173-178).

More disquieting challenges are looming. With new technologies such as synthetic biology and gene editing techniques, researchers are starting to court the idea of making better performing humans. A new technological myth of the superhuman is cherished (Warwick 2020). By using preferred gene variants preserved in computer databases and by unlocking genetic codes, it is possible to overcome the current biological boundaries of human performance and identify traits like disease resistance, powerful muscle, intelligence, that can be associated with real-life superheroes. As if the spark of life were migrating out of the human body and into the lab, it may soon be possible through selection and editing of genetic variants to intervene on living organisms and on the human body to produce genetic sequences that provide human embryos with the traits of the outliers, or create babies immune from diseases (Metzl 2019). How the 
traditional paradigm of human rights obligations may help prevent or mitigate such future dystopic scenarios is to be seen (Metzl 2020).

\section{Conclusions: Towards a 'Digital New Deal'?}

It seems that we are confronted with systemic threats from all angles in this 21 st century. Like climate change, digital technologies present unprecedented human rights dilemmas. Digitalization was supposed to be an equalizer of access, opportunities and resources, the condition for enhanced community-making and democracy-building. Instead, it prosecutes exacerbating extractive and exclusionary social outcomes and consolidating the totalizing pattern of neoliberal economic globalization, in the absence of international normative cooperation. There should be no excuses for further lethargy: data and digital systems are not going away, with considerable cross border effects.

COVID-19 has highlighted the state's pivotal function and the public notion of economic interest. The shaping of institutional frameworks and governance processes of data and digital systems will mark the battle ground between the hegemony of the few and the democratic future of the many. It is possible to move towards a 'Digital New Deal' akin to Roosevelt's Keynesian revolution (Just Net Coalition and IT for Chance 2021), whereby the state regulatory capacities are strengthened, to tackle the opacity of tech companies' business operations and to tighten the privacy rules of already vulnerable individuals, particularly because during the pandemic public health has been used to justify a rollback of existing legislations. Supranational entities might consider leveraging access to the markets of their members to force tech companies into compliance with such regulations - a possible blueprint of this approach may be the EU Digital Service Act regulation. The state fiscal capacities also need to be enhanced, possibly with the introduction of a $25 \%$ global minimum effective corporate tax rate on all profits earned by tech multinationals, as proposed by the Independent Commission for the Reform of International Corporate Taxation (Ocampo 2020). Finally, time has come for an intergovernmental negotiation on a new treaty - a Convention for Data and Cyberspace - which should contain explicit principles for extending well-established offline legal obligations to the online world (Hill 2021).

We need to engage and direct the purpose of data-based intelligence towards the ideal of digital public goods, if we are to reaffirm the chant of human intelligence, its diversity and divergence. Ultimately, the reasons of human rights law.

\section{Notes}

1. At the end of $2019,67 \%$ of the global population had subscribed to mobile devices, of which $65 \%$ were smartphones - with the fastest growth in Sub-Saharan Africa (GSMA, The mobile economy 2020, https://www.gsma.com/mobileeconomy/). In 2019, 204 billion apps were downloaded, with impressive growth in China (https://techcrunch.com/2020/01/15/app-stores-saw-record-204-billion-appdownloads-in-2019-consumer-spend-of-120-billion/), and as of January 2020, 3.8 billion people actively used social media (Simon Kemp, Digital 2020: Global Digital Overview, in Data Reportal, 30 January 2020, https://datareportal.com/reports/digital-2020-global-digital-overview/). But these numbers should not lead to hastily optimistic conclusions.

2. United Nations Development Programme (UNDP), Sustainable Development Goal 9: Industrial Innovation and Infrastructure, https://www.undp.org/content/undp/en/home/sustainable-development-goals/goal-9-industry-innovation-and-infrastructure.html, accessed 14 August 2020.

3. In developed countries, most people are online, with close to $87 \%$ of individuals using the internet. This number drops to a meagre $19 \%$ in the least developed countries (LDCs); see https://www.itu. int/en/ITU-D/Statistics/Documents/facts/FactsFigures2019.pdf. 
4. Women were absent as a hate-specific target group in the taxonomy of the research conducted by the European Commission, in compliance with the Code of Conduct on Countering Illegal Hate Speech Online released in May 2016.

5. Several studies exist in relation to the potential discriminations associated to the use of artificial intelligence and particularly algorithms. Among the many, we highlight Hard M. (2014), 'How big data is unfair. Understanding unintended sources of unfairness in data driven decision making', Medium, $26^{\text {th }}$ September 2014,https://medium.com/@mrtz/how-big-data-is-unfair-9aa544d739de; Barocas S. and Selbst A. (2016), 'Big Data's Disparate Impact', California Law Review, 104:671, 2016, http://dx.doi. org/10.2139/ssrn.2477899; Jon Kleinberg J., Ludwig J. et al. (2018), 'Discrimination in the age of algorithms', Journal of Legal Analysis, Volume 10, 2018, pp. 113:174, https://academic.oup.com/jla/article/ doi/10.1093/jla/laz001/5476086, accessed 29 $9^{\text {th }}$ December 2020.

6. In her first speech as Managing Director of the International Monetary Fund, Kristalina Georgieva alluded to a "digital Berlin Wall" the forces countries to choose between either technology systems. https://www.imf.org/en/News/Articles/2019/10/03/sp100819-AMs2019-Curtain-Raiser.

7. Sophia is a social humanoid robot developed by Hanson Robotics, based in Hong Kong. It was first activated on 14th February 2016, and made its debut in mid-March 2016, in Austin, Texas. Sophia robot is capable to display over 50 facial expressions, https://en.wikipedia.org/wiki/Sophia (robot).

8. https://www.youtube.com/watch?v=BqB4ZOdNY7s

9. See the Asilomar Principles initiative (2017), to the OECD Council Recommendations on Artificial Intelligence (2019), to the Human-Centred AI Principles by the G20 (2019).

10. The DSM directive is merely regulating the status quo created by the unrestrained actions of big corporations such as Google, curbing the rights and protections of authors of online contents and smaller operator. See on this, Bridy A. (2020), "The Price of Closing the "Value Gap": How the Music Industry Hacked EU Copyright Reform”, in 324 Vand. Journal of Entertainment. E Technology Law, Vol. 22, pp. 323-358.

11. See the diplomatic process around a Binding Treaty on transnational corporations' business activities and human rights at the UN Human Rights Council (UNHRC) https://www.ohchr.org/en/hrbodies/hrc/wgtranscorp/pages/igwgontnc.aspx.

12. https://www.nature.com/articles/s41591-020-1011-4/figures/1

\section{References}

AI Now Institute (2018) Litigating Algorithms: Challenging Government Use of Algorithmic Decision-Making, an AI Now Institute Report, in collaboration with Centre on Race, Inequality and the Law Electronic Frontier Foundation.

Al Dahdah, M. (2019) 'When Digital Giants Care for Africa:The Mobile Phone as a New Global Health Tool', Politique Africaine 156(4), 101-119.

(2020) 'Mobile Phones, Promoters of Behavioural Health in the Global South', Réseaux 219(1), 39-69.

Allen, G.C. (2017) 'Putin and Musk are right: Whoever masters AI will run the world', CNN, 5 September 2017, https://edition.cnn.com/2017/09/05/opinions/russia-weaponize-ai-opinion-allen/index.html [accessed 17 August 2020].

Alliance for Affordable Internet (A4AI) (2014) 'A4AI Mozambique Multi-stakeholder Forum', 29 June 2014, https://a4ai.org/mozambique-africa/ [accessed 12 August 2020].

Alston, P. (2019a) 'Report of the UN Special Rapporteur on extreme poverty and human rights', 74th Session of the General Assembly, A/74/48037, available at https://www.ohchr.org/EN/NewsEvents/ Pages/DisplayNews.aspx?NewsID=25156 [accessed 4 August 2020]

(2019b) Statement by Prof. Philip Alston, Special Rapporteur for extreme poverty and human rights, 74th Session of the General Assembly, Third Committee, Item 7 (c), 18 October 2019, http:// statements.unmeetings.org/media2/21999189/sr-extreme-poverty-ga-3rd-cttee-statement-f.pdf [accessed 7 August 2020]. 
Blix, M. (2017) Digitalization, Immigration and the Welfare State, Edward Elgar Publishing, https://www. elgaronline.com/view/9781786432940/9781786432940.xml [accessed 22 August 2020].

Brennen, J.S. and Kreiss, D. (2016) 'Digitalization', The International Encyclopedia of Communication Theory and Philosophy, 28 October 2016, 1-11.

Buchanan, M. (2019) 'Poverty in the UK is "systematic" and "tragic", says UN special rapporteur', BBC News, 22 May 2019, https://www.bbc.com/news/uk-48354692 [accessed 13 August 2020].

Budd, J. et al. (2020) 'Digital technologies in the public health response to COVID-19', Nature Medicine 26, 1183-1192, 7 August 2020, https://www.nature.com/articles/s41591-020-1011-4 [accessed 23 August 2020].

Burgess, M. (2020), 'Co-op is using facial recognition tech to scan and track shoppers', Wired, 10 December 2020, https://www.wired.co.uk/article/coop-facial-recognition [accessed 16 August 2020].

Cawley, J. (2014) 'The Affordable Care Act Permits Greater Financial Rewards For Weight Loss: A Good Idea In Principle, But Many Practical Concerns Remain', Journal of Policy Analysis and Management 33(3): 810-820, doi: 10.1002/pam.21767 [Accessed 29 August 2020].

Chesney, R. and Citron, D. (2018) 'Deepfakes: A Looming Crisis for National Security, Democracy and Privacy?', Lawfare, 21 February 2018, https://www.lawfareblog.com/deepfakes-looming-crisisnational-security-democracy-and-privacy [accessed 26 August 2020].

Children's Commissioner (2020) 'Tackling the disadvantage gap during the Covid-19 crisis', Briefing note, April 2020, https://www.childrenscommissioner.gov.uk/wp-content/uploads/2020/04/cco-tacklingthe-disadvantage-gap-during-the-covid-19-crisis.pdf [accessed 18 August 2020].

Daño, N. and Prato, S. (2019) 'The Real Technology Revolution:Technology Justice', Development 62(1-4), October 2019, https://doi.org/10.1057/s41301-019-00230-3 [accessed 17 August 2020].

Dilci, T. (2019) 'A Study on Validity and Reliability of Digital Addition Scale for 19 Years or Older', Universal Journal of Educational Research 7(1), January 2019, https://www.hrpub.org/journals/article_info. php?aid=7641 [accessed 23 December 2020].

Duggal, R., Briddle, I. and Bagenal, J. (2018) 'Digital Healthcare: Regulating the Revolution', BMJ, 360: k6, https://doi.org/10.1136/bmj.k6 [accessed 22 August 2020].

The Economist (2017) 'The World's Most Valuable Resource is No Longer Oil but Data', 6 May 2017, https://www.economist.com/leaders/2017/05/06/the-worlds-most-valuable-resource-is-no-longeroil-but-data [accessed 10 August 2020].

(2018) 'Taming the titans: Google, Facebook and Amazon are increasingly dominant. How should they be controlled?', The Economist 426(9075).

Eubanks, V. (2018) Automating Inequality: How High-Tech Tools Profile, Police and Punish the Poor, Picador Paperbacks.

European Commission (2020) 'Shaping Europe's Digital Future', The European Data Market Study Update, 6 July 2020, https://ec.europa.eu/digital-single-market/en/news/european-data-market-study-update [accessed 22 December 2020].

European Union (2016) Regulation 2016/679 on the protection of natural persons with regard to the processing of personal data and on the free movement of such data, and repealing Directive 95/46/EC (General Data Protection Regulation), 27 April 2016, https://eur-lex.europa.eu/legal-content/EN/ TXT/?uri=CELEX:32016R0679 [accessed 28 August 2020].

Gartner Information Technology (n.d.) 'Digitalization', Gartner Glossary, https://www.gartner.com/en/ information-technology/glossary/digitalization [accessed 28 December 2020].

Gershgorn, D. (2018) 'If AI is going to be the world's doctor, it needs better textbooks', Quartz, 6 September 2018, https://qz.com/1367177/if-ai-is-going-to-be-the-worlds-doctor-it-needs-better-textbooks/ [accessed 20 August 2020].

Giridharadas, A. (2019) Winners Take All: The Elite Charade of Changing the World, Allen Lane, Penguin Random House.

Hawi, N.S., Samaha, M. and Griffiths, M.D. (2019) 'The Digital Addiction Scale for Children: Development and Validation', Cyberpsychology, Behaviour and Social Networking 22(12), 12 December 2019, https:// www.liebertpub.com/doi/10.1089/cyber.2019.0132 [accessed 23 December 2020]. 
Hill, R. (2021) 'A New Convention for Data and Cyberspace', A Digital New Deal: Visions of Justice in a Post-COVID World, January 2021, 181-200, January 2021, https://itforchange.net/digital-new-deal/ [accessed 15 January 2021].

(2018) 'Big Data: Ownership and Use in the Digital Age', in Seuba, X., Geiger, C. and Pénin, J. (eds). Intellectual Property and Digital Trade in the Age of Artificial Intelligence and Big Data, CEIPI-ICTSD Publications Series, (5). https://blogs.bmj.com/bmj/2020/01/14/ilona-kickbusch-the-dark-side-ofdigital-health/ [accessed 12 August 2020].

Human Rights Council (HRC) (2018) Report of the Special Rapporteur on the promotion and protection of the right to freedom of opinion and expression, A/HRC/38/35, June-July 2018, agenda item 3, https://documents-dds-ny.un.org/doc/UNDOC/GEN/G18/096/72/PDF/G1809672. pdf?OpenElement [accessed 23 December 2020].

IGI Global (2018) 'What is Digitalization', IT Strategy Follows Digitalization, https://www.igi-global.com/ chapter/it-strategy-follows-digitalization/183799 [accessed 28 December 2020].

Iglesias, C. (2020) 'The gender gap in internet access: using a women-centred method', Web Foundation Blog, 10 March 2020, https://webfoundation.org/2020/03/the-gender-gap-in-internet-access-usinga-women-centred-method/ [accessed 12 August 2020].

International Committee of the Red Cross (ICRC) (2017) 'Digital Technology and War', International Review of the Red Cross, March 2017, https://international-review.icrc.org/articles/digital-technologyand-war [accessed 22 December 2020].

International Telecommunication Union (ITU) (2019) 'Measuring Digital Development: Facts and Figures 2019', ITU Publications, https://www.itu.int/en/ITU-D/Statistics/Documents/facts/FactsFigures2019. pdf [accessed 10 August 2020].

The Just Net Coalition and IT for Change (2021) 'A Digital New Deal:Visions of Justice in a Post Covid World', January 2021, https://itforchange.net/digital-new-deal/ [accessed 15 January 2021].

Kalluri, R., Gillespie, R. et al. (2020) 'If We're Not Careful, Tech Could Hurt the Fight against COVID19', Scientific American, 18 May 2020, https://blogs.scientificamerican.com/observations/if-were-notcareful-tech-could-hurt-the-fight-against-covid-19/ [accessed 24 August 2020].

Kaye, D. (2019) 'Report of the UN Special Rapporteur on the promotion and protection of the right to freedom of opinion and expression', $74^{\text {th }}$ Session of the UN General Assembly, A/74/486, 9 October 2019, https://www.ohchr.org/Documents/Issues/Opinion/A_74_486.pdf, [accessed 27 December 2020].

Kickbush, I. (2020) 'The dark side of digital health', The British Medical Journal Blog, 14 January 2020.

Klein, N. (2020) 'Screen New Deal: Under Cover of Mass Death, Andrew Cuomo Calls in the Billionaires to Build a High-Tech Dystopia', The Intercept, 8th May 2020, https://theintercept.com/2020/05/08/ andrew-cuomo-eric-schmidt-coronavirus-tech-shock-doctrine/, [accessed 12 August 2020].

Loucks, J., Hupfer, S. et al. (2019) 'Future in the Balance? How countries are pursuing an AI advantage', Insights from Deloitte's State of AI in the Enterprise, $2^{\text {nd }}$ Edition Survey, Deloitte, 1 May 2019, https:// www2.deloitte.com/us/en/insights/focus/cognitive-technologies/ai-investment-by-country.html [accessed 17 August 2020].

Malabou, C. (2017) Métamorphoses de l'intelligence. Que faire de leur cerveau bleu?, Presses Universitaires de France.

Marr, B. (2020) 'The future of Lawyers: Legal Tech, AI, Big Data and Online Courts', Forbes, 17th January 2020, https://www.forbes.com/sites/bernardmarr/2020/01/17/the-future-of-lawyers-legal-tech-aibig-data-and-online-courts/?sh=51b885bff8c4 [accessed 13 August 2020].

Marsh, S. (2019) 'One in three councils using algorithms to make welfare decisions', The Guardian, 15 October 2019, https://www.theguardian.com/society/2019/oct/15/councils-using-algorithmsmake-welfare-decisions-benefits [accessed 17 August 2020].

Mattioli, D. (2020) 'Big Tech Companies Reap Gains as Covid-19 Fuels Shift in Demand', The Wall Street Journal, 29 October 2020, https://www.wsj.com/articles/amazon-sales-surge-amid-pandemic-drivenonline-shopping-11604003107 [accessed 17 August 2020]. 
McDonald, S. (2020a) ‘Coronavirus: a Digital Governance Emergency of International Concern', Centre for International Governance Innovation, 2 March 2020, https://www.cigionline.org/articles/coronavirusdigital-governance-emergency-international-concern [accessed 20 August 2020].

(2020b) 'The Digital Response to the Outbreak of COVID-19', Centre for International Governance Innovation, 30 March 2020, https://www.cigionline.org/articles/digital-response-outbreak-covid-19 [accessed 13 August 2020].

Metzl,J. (2019) 'Making Babies in the Year 2045', The New York Times, 10 April 2019, https://www.nytimes. com/2019/04/10/opinion/genetic-testing-privacy.html?auth=login-email\&login=email [accessed 20 December 2020].

(2020) Hacking Darwin: Engineering and the Future of Humanity, Sourcebooks.

Mintzer, A. (2020) 'Paying Attention: the Attention Economy', Berkeley Economic Review, 31 March 2020, https://econreview.berkeley.edu/paying-attention-the-attention-economy/ [accessed 17 August 2020].

Montacute, R. (2020) 'School Closures and Disadvantaged Students', The Sutton Trust, 19 March 2020, https://www.suttontrust.com/news-opinion/all-news-opinion/school-closures/ [accessed 14 August 2020].

Narayan, S. (2019) 'An Inconvenient Truth - The Problem with Data Quality In MedTech AI', Medium, 18 October 2019, https://medium.com/@swethaxnarayanan/an-inconvenient-truth-the-problemwith-data-quality-in-medtech-ai-476d7486dae0 [accessed 20 August 2020].

Obermeyer, Z., Powers, B. et al. (2019) 'Dissecting racial bias in an algorithm used to manage the health of populations', Science 366(6464), 447-453, 25 October 2019, https://science.sciencemag.org/content/366/6464/447 [accessed 18 August 2020].

Ocampo, J.A. (2020) 'Fiscalité: Il est impératif d'introduire un taux effectif minimum global d'imposition des multinationales d'au moins 25\%', Le Monde, 20 November 2020, https://www.icrict.com/icrictin-thenews/2020/11/26/fiscalit-il-est-impratif-dintroduire-un-taux-effectif-minimum-global-dimposition-des-multinationales-dau-moins-25- [accessed 15 January 2021].

Office of the High Commissioner for Human Rights (OHCHR) (2019) 'Governments and Internet companies fail to meet challenges of online hate', 21 October 2019, https://www.ohchr.org/en/NewsEvents/Pages/DisplayNews.aspx?NewsID=25174\&LangID =E [accessed 28 December 2020].

O'Neil, C. (2016) Weapons of Math Destruction: How Big Data Increases Inequality and Threatens Democracy, Penguin Books.

Organisation for Economic Co-operation and Development (OECD) (2018) 'Tax and Digitalization', OECD Paper, October 2018, https://www.oecd.org/tax/beps/tax-and-digitalisation-policy-note.pdf [accessed 3 October 2020].

(2019) 'Regulatory effectiveness in the era of digitalization', June 2019, https://www.oecd.org/ gov/regulatory-policy/Regulatory-effectiveness-in-the-era-of-digitalisation.pdf [accessed 22 December 2020].

Ramaswami, R., Bayer, R. and Galea, S. (2018) 'Precision Medicine from a Public Health Perspective', Annual Review of Public Health 39, 153-168, 1 April 2018, https://pubmed.ncbi.nlm.nih.gov/29166244/ [accessed 13 August 2020].

Sadin, E. (2019) Critica della Ragione Artificiale: Una Difesa dell'Umanità, Luiss University Press.

Saez, E. and Zucman, G. (2019) The Triumph of Injustice: How the Rich Dodge Taxes and How to Make Them Pay, W.W. Norton \& Co.

Sample, I. (2018) 'Exclusive: dramatic slowdown in global growth of internet access', The Guardian, 18 October 2018, https://www.theguardian.com/technology/2018/oct/18/exclusive-dramatic-slowdown-in-global-growth-of-the-internet [accessed 12 August 2020].

(2019) 'Universal internet access unlikely until at least 2050, experts say', The Guardian, 10 January 2019, https://www.theguardian.com/technology/2019/jan/10/universal-internet-access-unlikely-until2050-experts-say-lack-skills-investment-slow-growth [accessed 12 August 2020].

Serokell (2020) 'Artificial Intelligence vs. Machine Learning vs. Deep Learning: what's the Difference', Medium, 10 April 2020, https://medium.com/ai-in-plain-english/artificial-intelligence-vs-machinelearning-vs-deep-learning-whats-the-difference-dccce18efe7f [accessed 12 August 2020]. 
Shatkovsskaya, T.V., Epifanova, T.S. et al. (2018) 'A Legal Mechanism for Regulating the Digital Economy', CBU International Conference on Innovations in Science and Education, 21-23 March 2018, CBU Journal, October 2020, https://ideas.repec.org/a/aad/iseicj/v6y2018i0p763-767.html [accessed 27 August 2020].

Singh, J. P. (2020) 'Breaking up Big Tech: Separation of its Data, Cloud, and Intelligence Layers', IT for Change, Working Paper 9, June 2020, https://itforchange.net/sites/default/files/add/Regulating data_cloud_and_intelligence_-_Paper_9-21.pdf [accessed 20 August 2020].

Szymielevicz, K. (2020) 'Black-Boxed Politics: Opacity is a Choice in AI Systems', Medium, 17 January 2020, https://medium.com/@szymielewicz/black-boxed-politics-cebc0d5a54ad [accessed 14 August 2020].

UNCTAD (2019) 'Digital Economy Report 2019', UNCTAD Publications, https://unctad.org/en/PublicationsLibrary/der2109_overview_en.pdf [accessed 20 August 2020].

United Nations (2018) 'Secretary General's High-Level Panel on Digital Cooperation', July 2018, https:// www.un.org/en/digital-cooperation-panel/ [accessed 17 August 2020].

US Congress Joint Economic Committee (2017) 'America's Digital Divide', September 2017, https:// www.jec.senate.gov/public/_cache/files/ff7b3d0b-bc00-4498-9f9d-3e56ef95088f/the-digitaldivide-.pdf [accessed 21 st August 2020].

Walsh,A. (2017) 'Saudi Arabia grants citizenship to robot Sophia', Deutsche Welle, 28 October 2017, https:// www.dw.com/en/saudi-arabia-grants-citizenship-to-robot-sophia/a-41150856 [accessed 17 August 2020].

Warwick, K. (2020) 'Superhuman Enhancements via Implants: Beyond the Human Mind', Philosophies, MDPI, 5, 14, 10 August 2020, https://www.mdpi.com/2409-9287/5/3/14/htm [accessed 22 December 2020].

Zuboff, S. (2019) The Age of Surveillance Capitalism: The Fight for a Human Future and the New Frontier of Power, Public Affairs.

Zuckerberg, M. (2017) 'Building Global Community', Facebook, 16 February 2017, https://www.facebook. com/notes/mark-zuckerberg/building-global-community/10154544292806634/ [accessed 14 August 2020]. 